\title{
The Effect of Shot Peening Configurations on Residual Stress of Aluminium 5052
}

\author{
Khairul Anam*, Anindito Purnowidodo \\ Mechanical Engineering Department, Brawijaya University, \\ Jl. MT. Haryono 167, Malang, 65145, INDONESIA \\ *Corresponding Author
}

DOI: https://doi.org/10.30880/ijie.2019.11.05.007

Received 8 January 2019; Accepted 17 April 2019; Available online 10 August 2019

\begin{abstract}
The aim of this study is, by using finite element analysis (FEA), to investigate the residual stresses and the distributions on the surface of material after shot peening process. The material of aluminium alloy A5052 is assumed as bilinear isotropic hardening. The residual stresses for various combinations of velocity, shot angle, and ball diameter was calculated. In addition, for ball diameter variations, the residual stresses was calculated by using two and three dimensional modeling. Simulation results indicate the residual stresses especially compressive residual stress is increased with increasing the velocity, shot angle, and ball diameter. However, the maximum compressive residual stresses between two and three-dimensional modeling are almost similar where the compressive residual stresses are the main purpose of the shot peening process.
\end{abstract}

Keywords: Shot peening, residual stress, Aluminium 5052, Finite Element Analysis

\section{Introduction}

Shot peening process is a cold working process to improve the fatigue behavior and reduce corrosion of mechanical parts or components [1-5]. It produces compressive residual stress by bombarding the surface of the component with a small spherical shot at a relatively high velocity. After a collision between the component and the shot has occurred, a small plastic indentation is formed on the surface of the component. Subsequently, the elastically stressed subsurface layers tend to recover to the original dimension when the shot was eliminated (unloading). However, the continuity of the component in the elastic and the plastic zone does not allow to recover. Hence, a compressive residual stress field followed by tensile is applied in the component.

In recent years, the shot peening process is widely used in aerospace, automotive and power generation industries. In the aerospace industry, the process leads to a reduction in structural weight for a specified reliability level i.e. turbine disc, propellers, main rotor spindles, and gear components. In the automotive industry, it leads to small low-cost components i.e. springs, gears, connecting rods, camshafts, and torsion bars. And in the power generation industry, it leads to improving the mechanical properties of a component which offers the correction of undersized components. Generally, shot peening process increases fatigue life, resistance to corrosion fatigue, resistance crack propagation, and improve the operating performance of metallic components [2,6]. Moreover, the structural resistance to an impact such as shot peening is directly related to the structural integrity [7].

Several experimental, analytical, and numerical methods of the shot peening process have been reported. The experimental methods attempting to determine the residual stress distribution, fatigue life, and the influence of the shot, component, and process parameters. The analytical and numerical methods focusing on calculating the residual stress and plastic zone. However, the understanding of single and twin shot impact is still far from complete.

FEA modeling provides a powerful method for simulating the shot peening process [8]. Combined with modern computer hardware, the computational time for such an assessment has been reduced to a satisfactory level [9]. Besides, a numerical simulation is performed to minimize experimental conduct [10]. The dynamic of single or multiple shots with high velocity and other parameters can be taken in appropriate FEA. According to the research done 
by More, the results showed that residual stress intensity increase with increasing the velocity. By doing other parameters research, will lead to a good result in fatigue live improvement. By using the FEA model, it will reduce experimental cost [8]. Meguid investigation results also shown that numerical model can be developed to predict the residual stress of aluminium alloy after the shot peening process. It is capable to capture the main features of the induced residual stress field and also an effective tool for the control and optimization of the treatment [1]. Meo achieved that the use of the shot peening process would improve significantly the structural performance of welded joints [2]. Another researcher, Gallitelli, introduced an initial residual stress field due to shot peening within a complex geometry with the case of a gear using numerical analysis. The simulation is an efficient method to transfer the stress and plastic deformation fields due to shot peening process into the geometry of the component [11]. Kosiuczenko investigated the mechanical peening of titanium alloy by using numerical simulations. He found that the introduction of some changes into the developed finite element method model gives a possibility to form desired properties of the worked material [12].

\section{Numerical Methods}

The compressive stress distribution was analyzed by using Finite Element Analysis (FEA). The FEA condition of shot peening process was summarized in Table 1.

Table 1 - Shot peening configurations.

\begin{tabular}{lcc}
\hline \multicolumn{1}{c}{ Condition } & Variation & Remark \\
\hline Velocity, $\mathrm{v}(\mathrm{m} / \mathrm{s})$ & $50,75,100,125,150$ & 3D \\
\hline Shot Angle, $\alpha\left(^{\circ}\right)$ & $60,70,80,90$ & 3D \\
\hline Ball Diameter, $\mathrm{d}(\mathrm{mm})$ & $0.3,0.6,1.1,2.1$ & 2D and 3D \\
\hline
\end{tabular}

The FEA model of the component (target) was constructed based on the ASTM standard of B 851-04. Fig. 1 shows the test strip C of ASTM standard. And the FEA model of the shot was described as a ball with a diameter as summarized in Table 1. Fig. 2 shows the shot angle of the shot peening process.

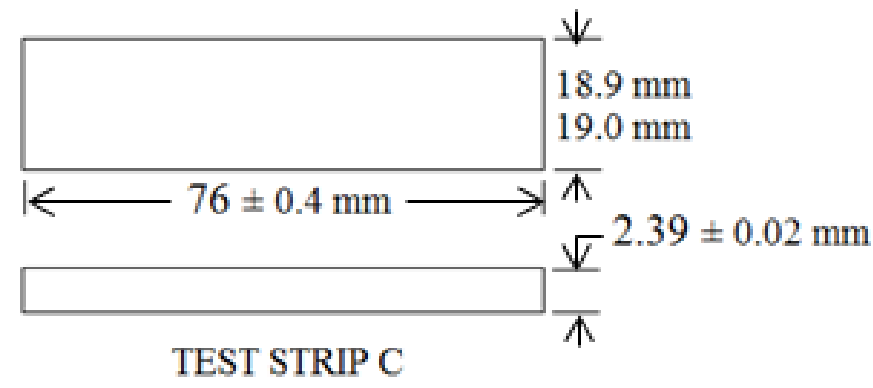

Fig. 1 - The test strip C of ASTM standard.

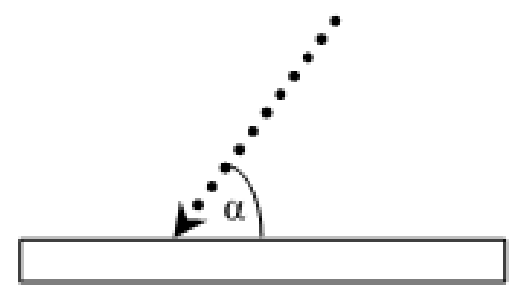

Fig. 2 - Shot angle.

\subsection{Material Properties}

The materials used in the component and the shot are modeled as bilinear isotropic hardening. It was summarized in Table 2 .

Table 2 - Material properties of the component and the shot. 


\begin{tabular}{lcc}
\hline \multicolumn{1}{c}{ Parameters } & $\begin{array}{c}\text { Component } \\
\text { (Aluminium 5052) }\end{array}$ & $\begin{array}{c}\text { Shot } \\
(\text { Steel) }\end{array}$ \\
\hline Density, $\rho\left(\mathrm{kg} / \mathrm{m}^{3}\right)$ & 2680 & 7800 \\
\hline Young's Modulus, E $(\mathrm{GPa})$ & 70 & 210 \\
\hline Poisson's Ratio, $v$ & 0.33 & 0.3 \\
\hline Yield Stress, $\sigma_{\mathrm{y}}(\mathrm{MPa})$ & 89.6 & 275 \\
\hline Ultimate Tensile Strength, UTS $(\mathrm{MPa})$ & 195 & 370 \\
\hline
\end{tabular}

\subsection{Finite Element Modeling}

In the present study, the residual stresses and the distributions on the component after the shot peening process was determined by a single shot. The component and the shot is a homogeneous materials and a solid (continuum) element with 4-node bilinear plane stress quadrilateral (CPS4R) and 8-node linear brick (C3D8R) for 2D and 3D, respectively. It is summarized in Table 3. A homogeneous material was used due to the material of the component and of the shot is an isotropic material. The solid elements can be used for elastoplastic analysis, complex nonlinear analysis involving contact and large deformations.

Table 3 - Mesh design.

\begin{tabular}{|c|c|c|c|}
\hline \multirow{2}{*}{ Dimension } & \multirow{2}{*}{ Mesh Design } & \multicolumn{2}{|c|}{ Number of Elements } \\
\hline & & Ball & Base Materials \\
\hline 2D (CPS4R) & & 30 & 1056 \\
\hline 3D (C3D8R) & & 25061 & 35950 \\
\hline
\end{tabular}

\subsection{Boundary Condition}

As summarized in Table 4, the bottom surface was under a plane-support condition such that the entire bottom surface was constrained with fixed support. The shot was under a velocity condition which differs as summarized in Table 1.

Table 4 - Boundary condition.

\begin{tabular}{ccc}
\hline $\begin{array}{c}\text { Boundary } \\
\text { Condition }\end{array}$ & 2D & 3D \\
\hline $\begin{array}{c}\text { Component } \\
\text { (Fixed } \\
\text { Support) }\end{array}$ & & \\
\hline
\end{tabular}


Shot

(Velocity)
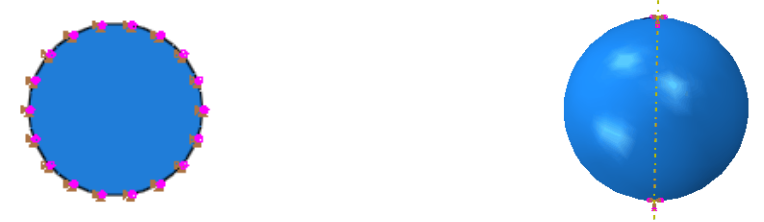

\section{Results and Discussions} 3.

The data collected as minimum principal stress. Data point in each parameter was choose in node as shown in Fig.

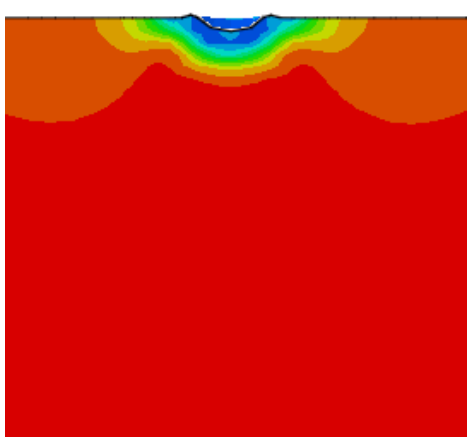

(a)

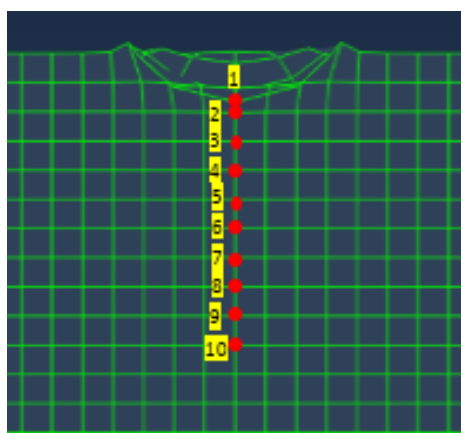

(b)

Fig. 3 - (a) Typical residual stress distribution using minimum principal stress; (b) Data point of residual stress.

\subsection{Effect of Velocity}

Fig. 4 shows the numerical residual stress distribution induced by shot peening for different velocity. Five different velocities of $50 \mathrm{~m} / \mathrm{s}, 75 \mathrm{~m} / \mathrm{s}, 100 \mathrm{~m} / \mathrm{s}, 125 \mathrm{~m} / \mathrm{s}$, and $150 \mathrm{~m} / \mathrm{s}$ were used in this study. The ball diameter and shot angle was used in the different velocity of $0.4 \mathrm{~mm}$ and $90^{\circ}$, respectively. From Fig. 4 reveal that the depth of the compressed layer and the maximum compressive residual stress increase with increasing the velocity. This phenomenon is compatible with the momentum equation [13]:

$$
P=m v
$$

Where $\mathrm{P}$ is momentum $(\mathrm{kg} \cdot \mathrm{m} / \mathrm{s})$, $\mathrm{m}$ is shot mass $(\mathrm{kg})$, and $\mathrm{v}$ is velocity $(\mathrm{m} / \mathrm{s})$. When mass constant, the momentum would increase by increasing the velocity. Stress after a collision would also increase. After the shot was resilience, plastic deformation would occur due to the stress after loading is higher than the yield stress. Fig. 5 shows the stress vector mechanism in loading and unloading condition. It reveals how the residual stress occurred in the component.

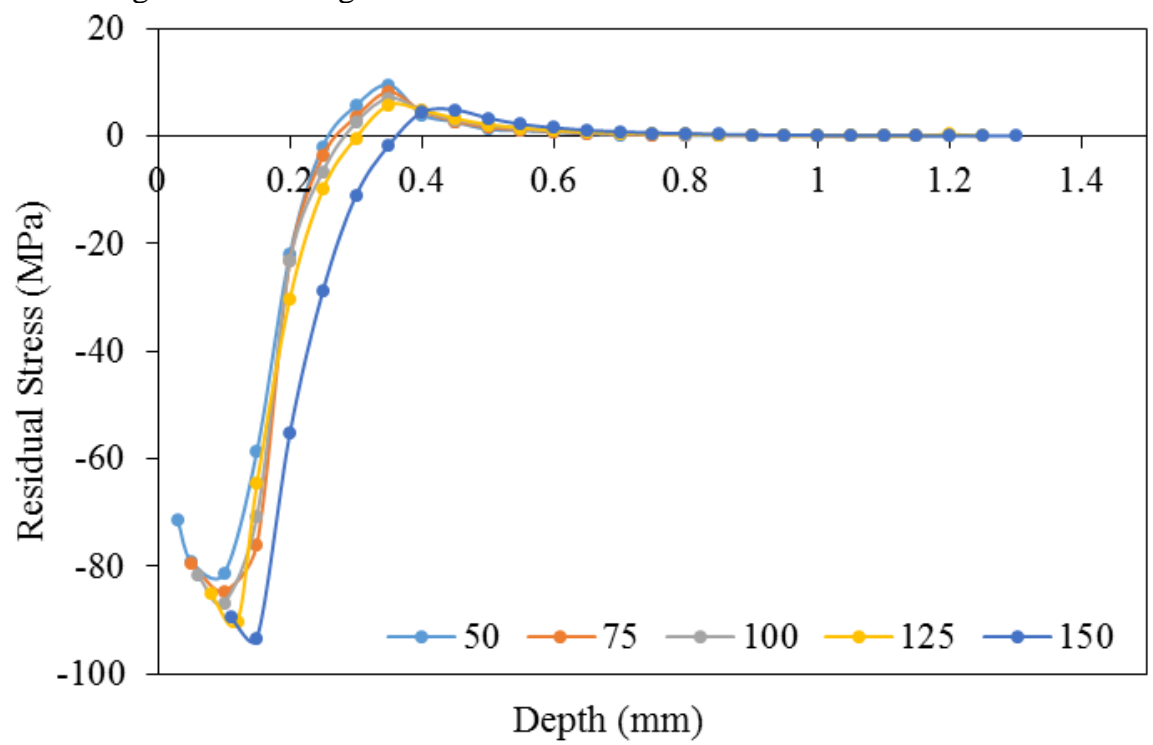

Fig. 4 - Numerical residual stress distribution induced by shot peening for different velocity. 


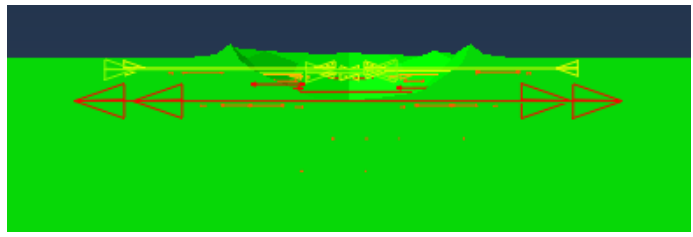

(a)

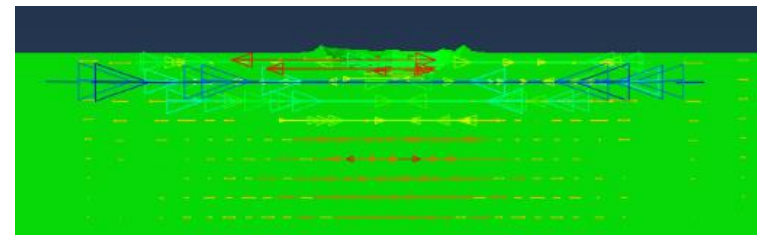

(b)

Fig. 5 - (a) Typical residual stress distribution using minimum principal stress; (b) Data point of residual stress.

\subsection{Effect of Shot Angle}

Fig. 6 shows the numerical residual stress distribution induced by shot peening for the different shot angle. Four different shot angles of $60^{\circ}, 70^{\circ}, 80^{\circ}$, and $90^{\circ}$ were used in this study. The ball diameter and velocity were used in the different shot angle of $0.4 \mathrm{~mm}$ and $100 \mathrm{~m} / \mathrm{s}$, respectively. From Fig. 6 show that the depth of the compressed layer and the maximum compressive residual stress increase with increasing the shot angle. This is occurred due to the stress transformation in another direction.

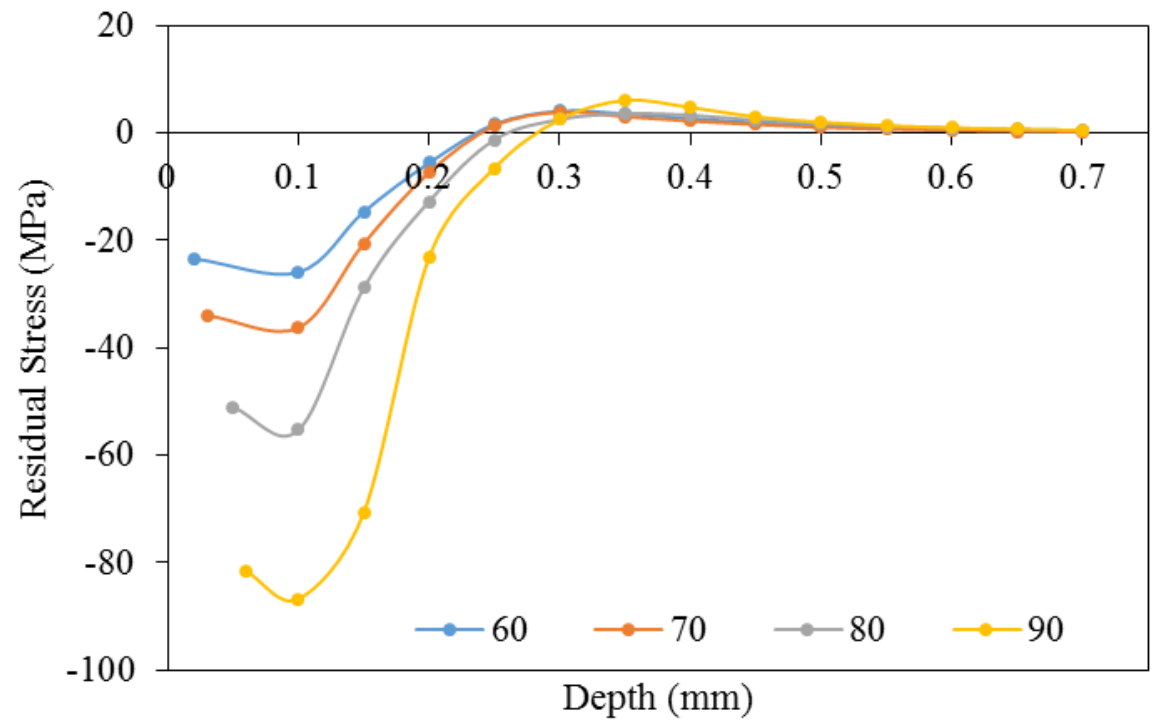

Fig. 6 - Numerical residual stress distribution induced by shot peening for the different shot angle.

\subsection{Effect of Ball Diameter}

Fig. 7 and 8 show the numerical residual stress distribution induced by shot peening for different ball diameter in 2D and 3D modeling, respectively. Four different ball diameter of $0.4 \mathrm{~mm}, 0.6 \mathrm{~mm}, 1.1 \mathrm{~mm}$, and $2.1 \mathrm{~mm}$ were used in this study. The shot angle and velocity was used in different ball diameter of $90^{\circ}$ and $50 \mathrm{~m} / \mathrm{s}$, respectively.

Fig. 7 shows that maximum residual stress increase with increasing the ball diameter. Though, the depth of the compressed layer is insignificantly changed. Interestingly, the results indicate that the difference residual stress of 0.6 $\mathrm{mm}$ and $1.1 \mathrm{~mm}$ is relatively high. This phenomenon might be occurred due to mesh density between the component and the shot. The mesh density will decrease with decreasing the size so that the mesh density of the component should be reduced either. However, the trend of the residual stress remains similar.

Similar to 2D modeling, the maximum residual stress in 3D modeling increase with increasing the ball diameter as shown in Fig. 8. The average of the depth affected by the shot peening process is $0.65 \mathrm{~mm}$. 


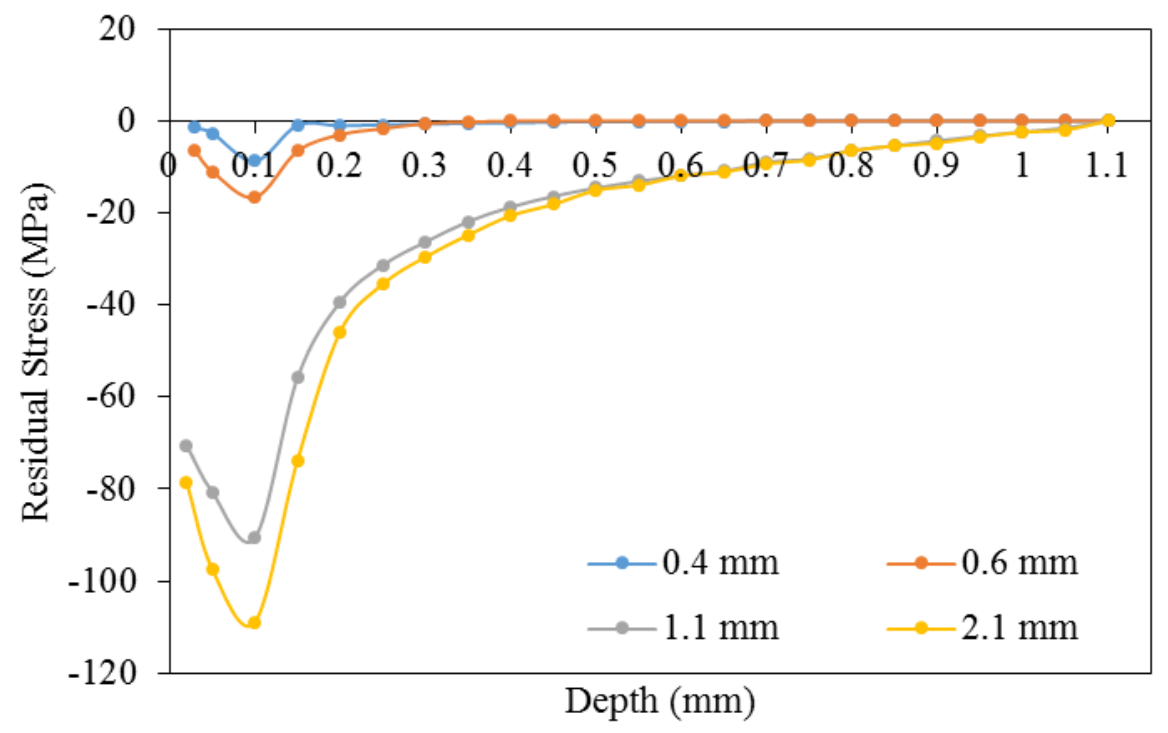

Fig. 7 - Numerical residual stress distribution induced by shot peening for different ball diameter in 2D modeling.

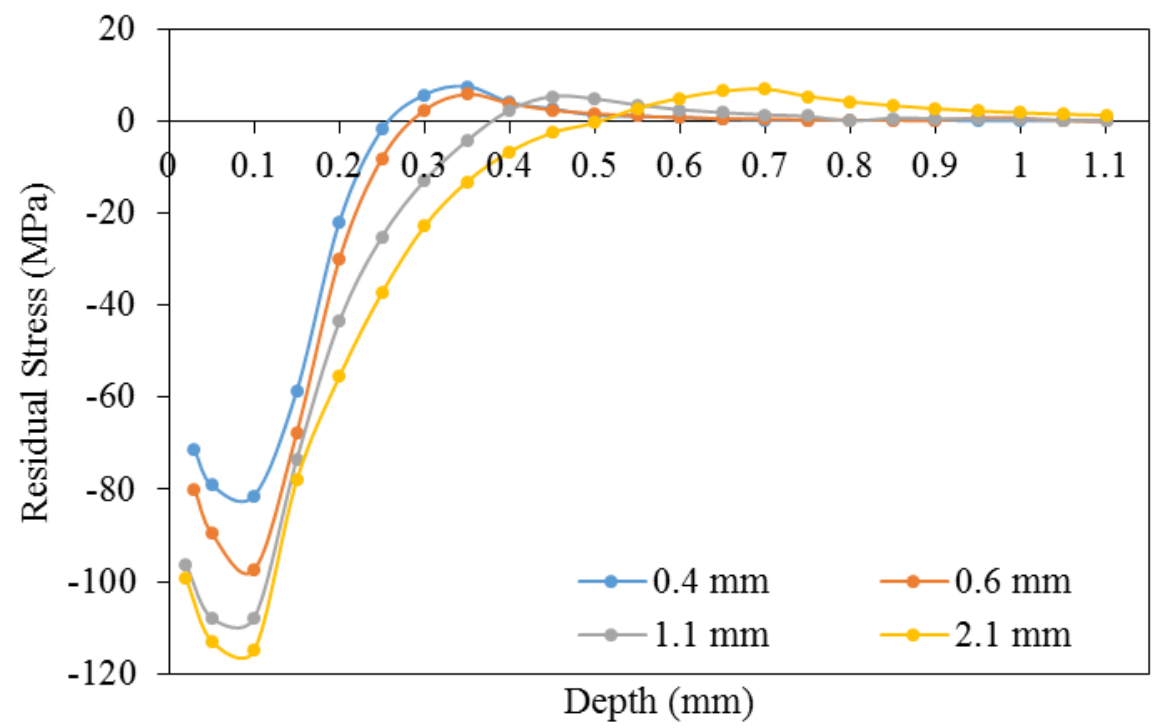

Fig. 8 - Numerical residual stress distribution induced by shot peening for different ball diameter in 3D modeling.

Fig. 9 shows the comparison of residual stress distribution between 2D and 3D modeling. The ball diameter and shot angle of $2.1 \mathrm{~mm}$ and $90^{\circ}$, respectively, were used to compare both modelings. Fig. 9 indicates that the maximum compressive residual stresses between two and three-dimensional modeling are almost similar where the compressive residual stresses are the main purpose of the shot peening process. The main advantage of $2 \mathrm{D}$ modeling is the simulation time is relatively shorter than 3D modeling. The simulation time of $2 \mathrm{D}$ and $3 \mathrm{D}$ modeling is around 20 minutes and 220 minutes, respectively. However, 3D modeling of the shot peening process was recommended due to closer to the original component. 


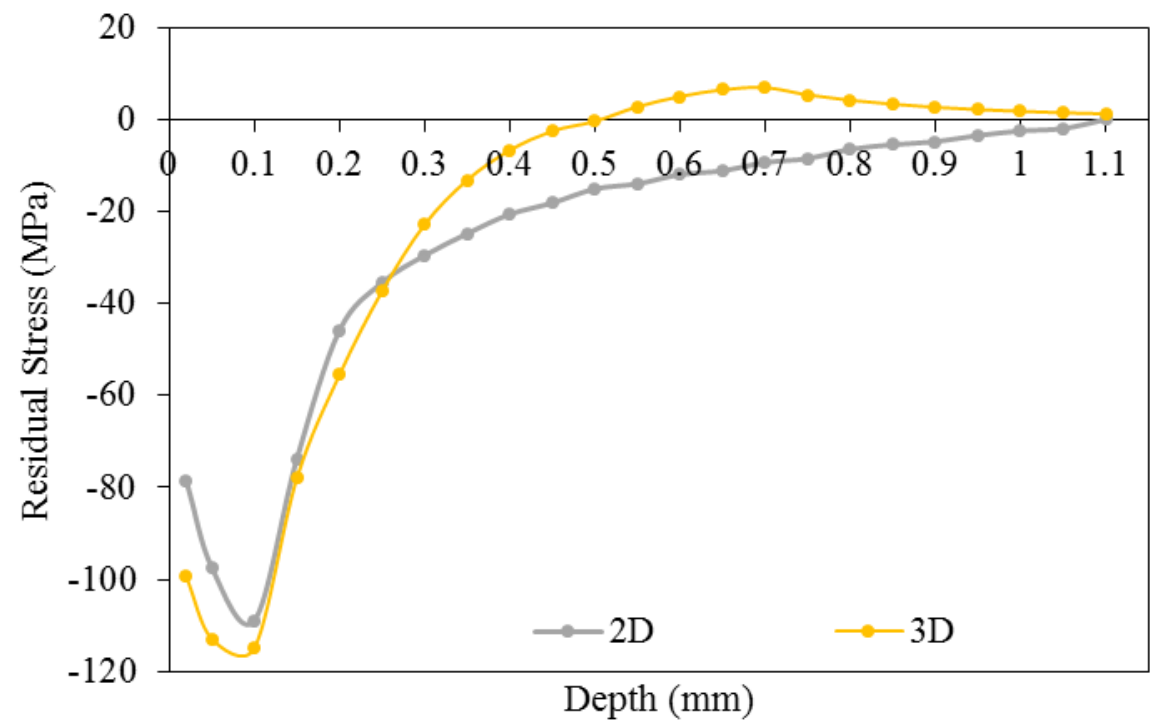

\section{Conclusion}

Fig. 9 - Comparison of residual stress distribution between 2D and 3D modeling.

The present study is used to analyze the residual stress after the shot peening process. The conclusions for this study are the residual stresses especially compressive residual stress is increased with increasing the velocity, shot angle, and ball diameter. However, the maximum compressive residual stresses between two and three-dimensional modeling are almost similar where the compressive residual stresses are the main purpose of the shot peening process.

\section{References}

[1] Meguid, S.A., Shagal, G., Stranart, J.C., and Daly, J. (1999). Three-dimensional dynamic finite element analysis of shot-peening induced residual stress. Finite Elements in Analysis and Design 31, pp. 179-191.

[2] Meo, M. and Vignjevic, R. (2003). Finite element analysis of residual stress induced by shot peening process. Advances in Engineering Software 34, pp. 569-575.

[3] Kim, T., Lee, H., Kim, M., and Jung, S. (2012). A 3D FE model for evaluation of peening residual stress under angled multi-shot impacts. Surface and Coatings Technology 206, pp. 3981-3988.

[4] Sherafatnia, K., Farrahi, G.H., Mahmoudi, A.H., and Ghasemi, A. (2016). Experimental measurement and analytical determination of shot peening residual stresses considering friction and real unloading behavior. Materials Science and Engineering A 657, pp. 309-321.

[5] Seddik, R., Seddik, M., Atig, A., and Fathallah, R. (2016). Thermo-mechanical relaxation of compressive residual stresses induced by shot peening. Procedia Structural Integrity 2, pp. 2182-2189.

[6] Jebahi, M., Gakwaya, A., Lévesque, J. Mechri, O., and Ba, K. (2016). A robust methodology to simulate real shot peening process using discrete-continuum coupling method. International Journal of Mechanical Science 107, pp. 21-33.

[7] Rahman, N.A., Abdullah, S., Abdullah, M.F., Omar, M.Z., Sajuri, Z., and Zamri, W.F.H. (2018). Ballistic limit of laminated panels with different joining materials subjected to steel-hardened core projectile. International Journal of Integrated Engineering. Vol. 10 No. 5, pp. 8-14.

[8] More, S.P. and Kulkarni, V.V. (2012). Finite element modeling for prediction of residual stress pattern from single shot impacting on aluminium (LM 13). International Journal of Engineering Research and Technology, pp. $1-6$.

[9] Mokhatar, S.N. and Abdullah, R. (2012). Computational analysis of reinforced concrete slabs subjected to impact loads. International Journal of Integrated Engineering, Vol. 4 No. 2, pp. $70-76$.

[10] Sulong, A.B., Radzuan, N.A.M., Mamat, M.R., Tharazi, I., Tholibon, D., Dweiri, R., and Hammadi, M.S. (2018). Kenaf Reinforced PLA Composite Thermoforming: A Numerical Simulation. International Journal of Integrated Engineering. Vol. 10 No. 5, pp. 15-20.

[11] Gallitelli, D., Boyer, V., Galineau, M., Colaitis, Y., Rouhaud, E., Retraint, D., Kubler, R., Desvignes, M., Barrallier, L. (2016). Simulation of shot peening: from process parameters to residual stress fields in a structure. Comptes Rendus Mecanique 344, pp. 355-374.

[12] Kosiuczenko, K. and Barnat, W. (2008). Numerical simulations of mechanical peening of titanium alloy. Journal of KONES Powertrain and Transport 15, pp. 137-144.

[13] Young, H., Freedman, R., Sears, F., and Zemansky, M. (1992). University Physics 8th Edition. 